\title{
Pengaruh Pemberian Akupresur oleh Anggota Keluarga terhadap Tingkat Nyeri Pasien Nyeri Kepala (Chephalgia) di Kota Padang Panjang
}

\author{
Rika Roza ${ }^{1}$, Budhi Mulyadi ${ }^{2}$, Yonrizal Nurdin ${ }^{3}$, Mahathir ${ }^{4}$ \\ 1 Puskesmas Gunung Kota Padang Panjang \\ ${ }^{2}$ Ketua STIKES Indonesial \\ ${ }^{3,4}$ Fakultas Keperawatan Universitas Andalas \\ Correspondence email: rikaroza01@gmail.com. bemulyadi74@gmail.com
}

\begin{abstract}
Abstrak. Nyeri kepala (Chephalgia) adalah keluhan yang sering dirasakan berupa ketidak nyamanan di daerah kepala, nyeri kepala dapat mengganggu aktifitas dan produktifitas. Salah satu terapi komplementer yang dapat mengurangi nyeri kepala adalah pemberian akupresur. Penelitian ini bertujuan untuk mengetahui pengaruh pemberian akupresur oleh anggota keluarga terhadap tingkat nyeri pasien nyeri kepala (Chephalgia) di Kota Padang Panjang yang dilakukan bulan Februari-September 2019. Penelitian ini Experiment Design dan rancangan penelitian pretest-postest with control group dengan jumlah sampel 116 orang dengan pengambilan sampel secara simple random sampling. Perbedaan tingkat nyeri sebelum dan sesudah pemberian akupresur oleh anggota keluarga digunakan Wilcoxon test. Sedangkan untuk melihat perbandingan kelompok intervensi dan kelompok kontrol digunakan untuk menguji dua kelompok yang berbeda digunakan mann withney test. Hasil uji statistik didapatkan nilai $\mathrm{p}=0.000$ ada pengaruh signifikan antara nyeri sebelum dan sesudah pemberian terapi akupresur pada kelompok intervensi sedangkan kontrol tidak ada perubahan yang signifikan dengan nilai $p=0,771$ Terapi akupresur ini direkomendasikan untuk mengatasi nyeri kepala (Chephalgia) yaitu memberikan bantuan terapi komplementer keperawatan untuk meminimalisir nyeri kepala (Chephalgia).
\end{abstract}

Kata kunci: nyeri kepala Chephalgia; terapi akupresur

Abstract. Chephalgia is grievance that is often felt like discomfort in head, Chephalgia can bother activity and productivity. One of complementary therapy that can reduce Chephalgia is acupressure. This study aims to determine the effect of acupressure by family member on pain level of Chephalgia patient in Padang Panjang conducted february-September 2019. The study is an experimental design and a pretest-posttest with control group design with 116 of samples and it uses simple random sampling. Different levels of pain before and after the administration of acupressure by family members used the Wilcoxon test. Whereas to see the comparison of the intervention group and the control group used to test two different groups used the mann withney test.. Satistic test result get $p$ value $=0.0000$ that means there is significant effect between before and after acupressure on intervention group, but there is no significant effect on control group get $p$ value $=0,771$. This therapy acupressure is recomended for solving Chephalgia, it means that we can give nursing complementary therapy for minimizing $C$.

Keywords: Chephalgia; acupressure

\section{PENDAHULUAN}

Nyeri kepala adalah rasa nyeri atau rasa tidak mengenakkan di seluruh daerah kepala dengan batas bawah dari dagu sampai daerah belakang kepala. (Lindsay KW, et al, 2010) Studi prevalensi memperkirakan setengah sampai tiga perempat orang dewasa berusia 18-65 tahun di dunia telah menderita sakit kepala pada tahun sebelumnya. Di dunia sekitar 50 persen orang yang mengalami nyeri kepala memilih untuk mengobati sendiri tanpa menggunakan fasilitas dan tenaga kesehatan.

Data Rikesdas 2013 proporsi pemanfaatan pelayanan kesehatan tradisional meningkat dari $30,4 \%$. (Fanani dan Bahrudin, 2013) Meningkat jadi 31,4\%. Proporsi jenis upaya kesehatan tradisional yang dimanfaatkan adalah ramuan jadi $48 \%$, ramuan buatan sendiri $31,8 \%$, keterampilan manual $65,3 \%$, keterampilan olah piker $1,9 \%$, dan keterampilan energi $2,1 \%$. Data WHO (2011), sebanyak $50-75 \%$ orang dewasa usia 18 - 65 tahun di dunia mengalami sakit kepala. $10 \%$ dari jumlah tersebut mengalami Chephalgia dan 1,7-4\% dari populasi orang dewasa menderita nyeri kepala selama 15 hari atau lebih setiap bulannya. (MacGregor E.A, et al, 2011)

Akibat yang ditimbulkan oleh nyeri kepala yang berlebihan mengganggu aktivitas sehari-hari (activities of daily living atau ADL), menurunkan kualitas hidup, dan meningkatkan beban ekonomi. Seseorang dapat mengalami hambatan dalam menjalani aktivitas bila tengah mengalami nyeri kepala (Chephalgia). (Martelletti $P$, et al, 2017) Penelitian yang telah dilakulakan menunjukkan bahwa terjadi penurunan produktivitas kerja saat mengalami nyeri kepala sebanyak $81 \%$ responden pada penelitian itu mengalami penurunan produktivitas kerja sebanyak lebih dari $20 \%$ dan $90 \%$ responden menyatakan tidak hadir bekerja setidaknya satu hari dalam setahun dikarenakan nyeri kepala. (Vinding G, et al, 2017) Selain itu 94\% responden pada penelitian itu menyatakan nyeri kepala mengganggu aktivitas pekerjaan rumah, $96 \%$ responden menyatakan nyeri kepala mengganggu aktivitas sosial, dan 91\% responden menyatakan nyeri kepala mengganggu hubungan antar anggota keluarga. Jadi dampak yang terjadi jika mengalami nyeri kepala akan menurunkan kualitas hidup, meningkatnya beban ekonomi, dan akan menggangu aktifitas seseorang.

Ada beberapa penyebab terjadinya nyeri kepala (Chephalgia). Penelitian yang telah dilakukan mengatakan bahwa faktor penyebab nyeri kepala adalah psikologi atau emosional seseorang yang tinggi. (Fanani dan Bahrudin, 2013) Nyeri kepala ini diakibatkan oleh karena pembuluh darah yang menuju otak mengalami vasokontriksi yang disebabkan oleh karena adanya peningkatan kadar serotonin dan kemudian mengalami vasodilatasi- (Funaidi, 2013) Faktor penyebab nyeri 
kepala adalah kecemasan. Penyebab lain nyeri kepala adalah karena kurang tidur. (Sukmana R, 2012)

Ada beberapa upaya yang dilakukan oleh masyarakat dalam menangani nyeri kepala (Chephalgia). Salah satu upaya yang dilakukan untuk penangan nyeri adalah dengan cara menkonsumsi obatobatan yang seperti analgesik dan NSAID (non-steroidal antiinflammatory drugs). (Anurogo, 2012) Upaya lain yang dilakukan untuk penanganan nyeri Chephalgia yakni dengan akupresur. Akupresur pada acupoint taichong dapat menurunkan nyeri kepala dan blood pressure pada pasien hipertensi dan dapat dimasukkan dalam rencana perawatan untuk hipertensi. (Lin G.-H, et al, 2016) penelitian yang telah dilakukan mengatakan tindakan akupresur dapat menurunkan nyeri kepala dan hipertensi. Masalah kesehatan yang mampu dikurangi oleh akupresur yakni meredakan pasiendyspnoea, kecemasan, dan mengurangi indikator fisiologis kecemasan pada pasien yang memiliki dukungan ventilasi mekanis dan nyeri. Chephalgia pada pasien berusia menengah dan lanjut usia dapat menurunkan hipertensi dan nyeri Chephalgia. (Zheng L, 2014)

Salah satu asuhan keperawatan yang pemberian asuhannya dengan menggunakan pengobatan dan alat tradisional yang sering disebut asuhan keperawatan komplementer. Keperawatan komplementer terdiri dari invasif dan non-invasif. Contoh dari terapi komplementer invasif adalah akupuntur dan bekam, sedangkan terapi non invasif terdiri dari terapi energi, terapi biologis, dan terapi sentuhan modalitas seperti akupresur, pijat bayi, refleksi dan lain lain. Jadi dapat disimpulkan keperawatan komunitas melihat bagaimana mengatasi masalah penyakit di masyarakat dan salah satu pengobatannya bisa dengan pengobatan tradisional yang bisa di sebut dengan asuhan keperawatan komplementer. (Omura, 2013)

Akupresur merupakan suatu tindakan pengobatan tradisional keterampilan dengan cara menekan titik-titik akupuntur dengan penekanan menggunakan jari atau benda tumpul di permukaan tubuh. Kelebihan akupresur ini lebih rendah resiko, mudah dilakukan dan dipelajari, bermanfaat untuk menghilangkan nyeri dan relaksasi. Akupresur adalah terapi non-invasif yang didasarkan pada Pengobatan Tradisional Cina (TMC), dan mungkin menawarkan modalitas terapi yang berharga untuk mengelola gejala pada pasien ini. Akupresur merupakan aplikasi dari tekanan yang tegas dan terus menerus pada lokasi khusus pada area tubuh tertentu yang bertujuan menurunkan nyeri, menghasilkan relaksasi dan mencegah dan menurunkan mual. (Gloria M, 2016)

Dari fenomena di atas peneliti tertarik untuk melakukan penelitian pengaruh akupresur oleh anggota keluarga yang berperan dalam fungsi perawatan dan pemeliharaan kesehatan anggota keluarga agar memiliki produktifitas yang tinggi di kota Padang Panjang.

Tujuan dari penelitian ini untuk melihat pengaruh pemberian akupresur terhadap tingkat nyeri pasien nyeri kepala (Chephalgia) dikota Padang Panjang

\section{METODE}

Penelitian ini merupakan penelitian kuantitatif. Desain penelitian yang digunakan dalam penelitian ini adalah quasi eksperimen dengan rancangan pre-test - post-tes twith control graoup design adalah dimana desain ini mengambil secara random sampling menjadi 2 kelompok. Satu kelompok adalah kelompok perlakuan, sedangkan kelompok lain adalah sebagai kelompok kontrol atau pembanding. (Harrison, 2012) Populasi Dalam Penelitian ini adalah pasien nyeri kepala( Chephalgia) yang datang berkunjung di puskesmas kota Padang Panjang.Penelitian dilakukan mei 2019 sampai dengan juni 2019. Jumlah sampel pada penelitian ini 116 yang dibagi menjadi 2 kelompok , 58 responen untuk kelompok intervensi dan 58 untuk kelompok kontrol.

\section{HASIL PENELITIAN}

Setelah dilakukan penelitian karakteristik kelompok intervensi dan kelompok kontrol memilili data yang setara atau homogen. ( $p$ value $\geq 0.05$ ). Secara ringkas hasil disajikan pada tabel

Tabel. 1. Distribusi Frekuensi Karakteristik Responden Pengaruh Pemberian Akupresur terhadap Tingkat Nyeri Pasien Nyeri Kepala (Chephalgia) di Kota Padang Panjang Tahun 2019

\begin{tabular}{|c|c|c|c|c|c|}
\hline \multirow[t]{2}{*}{$\begin{array}{l}\text { Karakteristik } \\
\text { Responden }\end{array}$} & \multicolumn{2}{|c|}{$\begin{array}{c}\text { Kelompok } \\
\text { Intervensi } \\
(n=58)\end{array}$} & \multicolumn{2}{|c|}{$\begin{array}{c}\text { Kelompok } \\
\text { Kontrol } \\
(n=58)\end{array}$} & \multirow[t]{2}{*}{$\begin{array}{c}\text { Uji } \\
\text { Homogenitas } \\
(p \text {-value })\end{array}$} \\
\hline & $\mathbf{F}$ & $\%$ & $f$ & $\%$ & \\
\hline \multicolumn{6}{|l|}{ Umur } \\
\hline - Dewasa & 32 & 55,2 & 38 & 65,5 & 1,000 \\
\hline $\begin{array}{l}\text { - Dewasa tua } \\
\text { Jenis Kelamin }\end{array}$ & 26 & 44,8 & 20 & 34,5 & \\
\hline - Laki-Laki & 24 & 41,4 & 20 & 34,5 & 0,142 \\
\hline $\begin{array}{l}\text { - Perempuan } \\
\text { Pekeriaan }\end{array}$ & 34 & 58,6 & 38 & 65,5 & \\
\hline - PNS & 29 & 50,0 & 23 & 39,7 & \\
\hline - swasta & 26 & 44,8 & 29 & 39.7 & 0,185 \\
\hline - IRT & 3 & 5.2 & 6 & 10,3 & \\
\hline
\end{tabular}

Tabel.1 memperlihatkan umur pasien pada kelompok intervensi dan kontrol sebagian besar dewasa, berjenis kelamin perempuan dan pekerjaan adalah pegawai negeri .Hal ini berkaitan dengan sakit kepala sering terjadi pada usia dewasa atau usia produktif bekerja. (Harrison, 2012) Faktor-faktor yang berpengaruh pada nyeri diantaranya usia, jenis kelamin, pekerjaan, kebudayaan, perhatian, ansietas, pengalaman sebelumnya, dukungan keluarga.

Berdasarkan table 2 uji analisis terlihat nilai $\mathrm{p}$ value $=0,000$. maka dapat kita simpulkan ada perbedaan yang signifikan antara tingkat nyeri pada kelompok intervensi sebelum dan sesudah perlakuan pemberian akupresur oleh anggota keluarga dimana nilai $P<0.05$. Sedangkan pada kelompok kontrol yang tidak diberi perlakuan pemberian akupresur oleh anggota.berdasarkan hasil uji analisis terlihat nilai $\mathrm{p}$ value $=0,771$ maka dapat disimpulkan tidak ada perbedaan yang signifikan antara tingkat nyeri pada kelompok kontrol. 


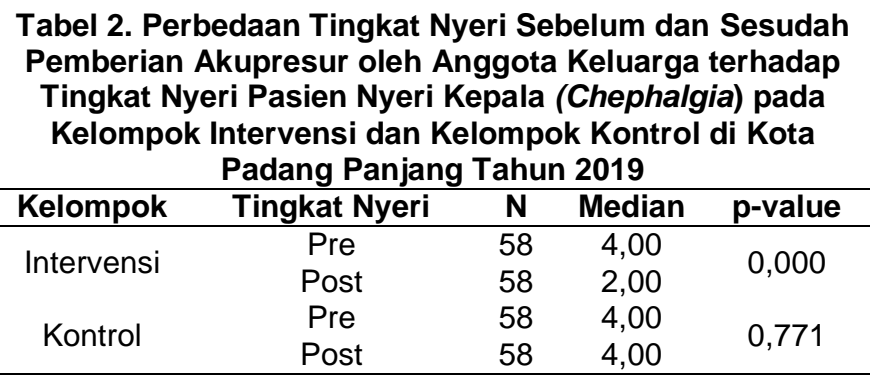

Perbandingan tingkat nyeri pasien nyeri kepala dinilai sesudah pemberian akupresur oleh anggota keluarga pada kelompok intervensi. Selain itu pada kelompok kontrol juga dilakukan penilaian tingkat nyeri pasien nyeri kepala (Chephalgia) walaupun tidak dilakukan akupresur pada kelompok kontrol. Perbandingan ini dianalisa dengan menggunakan uji Mann Whitney, yang dapat dilihat pada tabel 3 di bawah ini.

\begin{tabular}{|c|c|c|}
\hline \multicolumn{3}{|c|}{$\begin{array}{l}\text { Tabel 3. Distribusi Pengaruh Pemberian Akupresur oleh } \\
\text { Anggota Keluarga terhadap Tingkat Nyeri Pasien Nyeri } \\
\text { Kepala (Chephalgia) Kelompok Intervensi dan Kelompok } \\
\text { Kontrol Setelah Diberikan Perlakuan Pemberian } \\
\text { Akupresur di Kota Padang Panjang Tahun } 2019\end{array}$} \\
\hline Tingkat Nyeri & Median & p-value \\
\hline $\begin{array}{c}\text { Intervensi } \\
\text { Kontrol }\end{array}$ & $\begin{array}{l}2,00 \\
4,00\end{array}$ & 0,000 \\
\hline
\end{tabular}

Pada tabel.3 Hasil uji Mann Whitney tersebut menunjukan bahwa nilai $p$ - value pada kelompok intervensi dan kelompok kontrol terlihat nilai $p$-value $=$ 0,000 maka dapat disimpulkan terdapat perbedaan yang signifikan tingkat nyeri pada kelompok intervensi dan kelompok kontrol.

\section{PEMBAHASAN}

Berdasarkan penelitian yang dilakukan perbedaan skor sebelum dan sesudah pemberian akupresur akupresur dan pada kelompok kontrol tidak mendapatkan terapi akupresur. Berdasarkan uji statistik terlihat nilai $p$-value $=0,000$ maka dapat disimpulkan perbedaan yang signifikan tingkat nyeri pada kelompok intervensi. Penelitian ini sejalan dengan penelitian yang dilakukan oleh peneliti sebelumnya tentang intensitas nyeri pada pada siswi sebelum dilakukan akupresur rata-rata tingkat nyeri ringan sedang dan berat. Setelah dilakukan pemberian akupresur nyeri berkurang dan hilang. (Hsieh, 2010)

Penelitian tentang akupresur juga dilakukan oleh penelitian lain, tentang efektifitas akupresur untuk nyeri kepala kronis dibanding obat pelemas otot yang di ujikan pada 28 pasien yang di pilih secara random, didapat hasil penelitian yang menunjukan bahwa akupresur pada kelompok intervensi dengan sampel 14 orang secara signifikan rata-rata menurunkan skor nyeri yang di ukur dengan VAS (visual analog skale) yaitu $(32,9-26)$ dengan $\mathrm{p}=0,002$ sedangkan dari kelompok obat pelemas otot dengan sampel 14 orang didapat $(55,7=-$ 28,7) dengan $p=0,047$. (Enggal, 2016)

Hal ini sejalan dengan penelitian tentang efektifitas akupresur untuk nyeri kepala kronis dibanding obat pelemas otot yang di ujikan pada 28 pasien yang di pilih secara random, didapat hasil penelitian yang menunjukan bahwa akupresur pada kelompok intervensi dengan sampel 14 orang secara signifikan rata-rata menurunkan skor nyeri yang di ukur dengan VAS (visual analog skale) yaitu (32,9-26) dengan $\mathrm{p}=0,002$ sedangkan dari kelompok obat pelemas otot dengan sampel 14 orang didapat $(55,7=-28,7)$ dengan $p=0,047$. Akupresur merupakan suatu terapi komplementer yang dapat digunakan untuk menurunkan tinggkat nyeri akut maupun nyeri kronis di ukur melalui VAS (visual analog skale) dengan hasil yang signifikan dapat menurunkan tingkat nyeri. (Allais, et al, 2012) jadi akupresur efektif untuk mengurangi rasa nyeri di nyeri kepala maupun nyeri akut dan nyeri kronis. (Akbarnezhada, et al, 2018)

Akupresur adalah keperawatan komplementer yang menggunakan jari dan tangan untuk merangsang titik akupuntur, penelitian ini membuktikan akupresur dapat menhilangkan nyeri dan rasa sakit berbeda pada populasi yang berbeda. (Yeganeh, 2017) Akupresur adalah praktek yang tidak invasive, tidak menyakitkan, praktis hanya menggunakan jari sehingga pasien dapat diajarkan secara mandiri untuk bertanggung jawab terhadap perawatan mereka, akupresur sudah terbukti dapat mengobati rasa nyeri seperti nyeri haid, nyeri kepala kronis, nyeri punggung, nyeri leher termasuk nyeri persalinan. (Shari M, et al, 2017)

Pengobatan komplementer dan alternative seperti akupresur telah memainkan peranan untuk pengobatan kesehatan, akupresur didasari pada prinsip aktivasi acupoin di meridian yang berguna memperbaiki keseimbangan antara energy atau QI yang bertujuan untuk mengurangi rasa nyeri dan rasa sakit. Titik tekanan dengan teknik penekanan tangan dianggap sebagai pengelolaan berbagai gejala. Akupresur aman dilakukan karena tidak menggunakan alat yang menembus kulit, selain itu akupresur praktis dan murah karna membutuhkan jari tangan atau dengan alat yang minimal. (Mehta $\mathrm{P}$, et al, 2017)

Dukungan keluarga yang baik dapat mendukung pelaksanaan program terapi. Dukungan keluarga juga dapat menurunkan tingkat stress pasien yang sedang menderita penyakit. (Setyowati H, 2018) Tujuan pendidikan kesehatan keluarga adalah memberikan informasi sehingga klien dapat membuat keputusan terkait dengan kesehatan dan penyakit, Membantu klien berperan secara efektif dalam perawataan diri mereka, membantu klien beradaptasi dengan penyakitnya, membantu klien mencapai kepuasan melihat upaya mereka dalam meningkatkan kesehatan. (Friedman MM, et al, 2019) Supaya keluarga dapat menjadi sumber kesehatan primer dan efektif, keluarga harus lebih terlibat dalam tim perawatan kesehatan dan proses terapi secara total. (Cattan M, et al, 2010)

\section{SIMPULAN}

Pemberian Akupresur yang dilakukan oleh anggota keluarga berpengaruh terhadap nyeri kepala (Chephalgia).

\section{Saran}

Diharapkan keluarga dapat menerapkan akupresur dalam mengatasi dan mengurangi nyeri 
kepala (Chephalgia) dan dapat menjadi evidenc base untuk peneliti berikutnya.

\section{Ucapan Terima Kasih}

Terima kasih Civitas Fakultas Keperawatan Universitas andalas, Puskesmas sekota Padang Panjang dan Dinas Kesehatan Kota Padang Panjang serta semua pihak yang telah membantu proses penelitian ini.

\section{DAFTAR PUSTAKA}

Lindsay, K. W., Bone, I., \& Fuller, G. (2010). Neurology And Neurosurgery Illustrated. (5th, Ed.). Edinburg: Churchill Livingstone Elsevier.

MacGregor, E. A., Jason, D. R., \& Kurth, T. (2011). SexRelated Differences in Epidemiological and ClinicBased Headache Studies. Am Head Soc, 51, 843-859.

Martelletti, P., Steiner, T., Bertolote, J., Dua, T., \& Saraceno, B. (2017). Photic hypersensitivity in the premonitory phase of migraine - a positron emission tomography study. European Journal of Neurology, 21, 1178-1183.

Vinding, G., Zeeberg, P., Lyngberg, A., Nielsen, R., \& Jensen, R. (2017). The Burden of Headache in a Patient Population from a Specialized Headache Centre. Cephalalgia, 27, 263-270.

Fanani, A. K., Sys, I., \& Bahrudin, M. (2013). Kajian tentang kecemasan sebagai faktor risiko tension type headache (TTH).

Funaidi, S. (2013). Sakit Kepala, Migrain dan Vertigo. Jakarta: Gramedia.

Sukmana, R., Setiawan, M., \& Hasanah, A. (2012). Hubungan Tingkat Kecemasan Menghadapi Ujian Akhir Blok (UAB) Terhadap Resiko Terjadinya Tension-Type Headache (TTH) Pada Mahasiswi Fakultas Kedokteran Universitas Muhammadiyah Malang Angkatan 2008.

Anurogo, D. (2012). Education, 39(10), 731-737.

Lin, G.-H., Chang, W.-C., Chen, K.-J., Tsai, C.-C., Hu, S.-Y., \& Chen, L.-L. (2016). Effectiveness of Acupressure on the Taichong Acupoint in Lowering Blood Pressure in Patients with Hypertension: A Randomized Clinical Trial. Evidence-Based Complementary and Alternative Medicine, 2016, 1-9. https://doi.org/10.1155/2016/1549658

Zheng, L., Chen, Y., Chen, F., Zhang, P., \& Wu, L. (2014). ScienceDirect Effect of acupressure on sleep quality of middle-aged and elderly patients with hypertension. International Journal of Nursing Sciences, 1(4), 334-338. https://doi.org/10.1016/j.jinss.2014.10.012

Omura, Y. (2013). Acupuncture Medicine: Its Historical and Clinical Background. Dover Publications.

Gloria M. Bulechek, Howard K. .joanne M. Dochterman, C. M. W. (2016). Nursing Interventions Classification(NIC) (keenam). singapore: elsevier singapore pte Itd.

Harrison. (2012). Prinsip- prinsip ilmu penyakit dalam (7th ed.). Jakarta.

Hsieh, L. L., Liou, H., Lee, L., \& Chen, T. H. (2010). Effect of Acupressure and Trigger Points in
Treating Headache: A Randomized Controlled Trial, 38(1), 1-14.

Enggal HK. (Complementary and Alternative Medicine Acupresure in Reducing. 2016;1(2).

Allais, G., Rolando, S., Gabellari, I. C., Burzio, C., Airola, G., Borgogno, P., ... Benedetto, C. (2012). Acupressure in the control of migraine-associated nausea. Italy: Springer. https://doi.org/10.1007/s10072-012-1069-y

Akbarnezhada, N., Shahboulaghib, F. M., Khankehc, H., Sokhangouied, Y., Biglariane, A., \& Modanloof, S. (2019). The effect of acupressure therapy on pain, stiffness and physical functioning of knees among older adults diagnosed with osteoarthritis: A pilot randomized control trial. European Journal of Integrative Medicine, 28(August 2018), 68-75. https://doi.org/10.1016/..eujim.2019.04.007

Yeganeh M, Reza $H$, Qorbani M, Moradi Y. Complementary Therapies in Clinical Practice The effectiveness of acupuncture, acupressure and chiropractic interventions on treatment of chronic nonspeci fi c low back pain in Iran : A systematic review and meta-analysis. Complement Ther Clin Pract [Internet]. Elsevier Ltd; 2017;27:11-8. Available from: http://dx.doi.org/10.1016/j.ctcp.2016.11.012

Shari M, Shamsalinia A, Ghaffari F, Keyhanian S. Complementary Therapies in Clinical Practice The effect of acupressure on pain , anxiety, and the physiological indexes of patients with cancer undergoing bone marrow biopsy. 2017;29:136-41.

Mehta P, Dhapte V, Kadam S, Dhapte V. Journal of Traditional and Complementary Medicine Contemporary Acupressure Therapy: Adroit Cure for Painless Recovery of Therapeutic Ailments. J Tradit Chinese Med Sci Chinese [Internet]. Elsevier Ltd; 2017;7(2):251-63

Setyowati $\mathrm{H}$. Akupresur untuk kesehatan waita berbasis penelitian. Magelang: Unimma Press; 2018.

Friedman MM, Vicky R.Bowden, DNsc R, Elaine G. Jones, PhD, MS R. Buku Ajar Keperawatan keluarga: Riset, Teori, dan Praktek. 5th ed. Jakarta: EGC; 2019. 664 p.

Cattan M, White M, Bond J, Learmouth A. Preventing Social Isolation and Loneliness Among Older People: a Systematic Review of Health Promotion Interventions. J Ageing Soc. 2010;25(1):41-6 